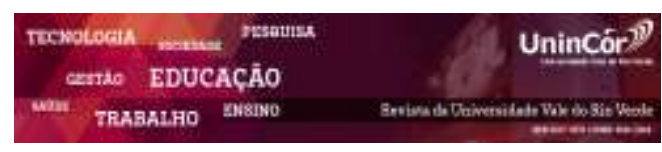

Revista da Universidade Vale do Rio Verde ISSN: 1517-0276 / EISSN: 2236-5362 Vol. 16 | n. 2 | Ano 2018

Cláudia Pereira da Silva Universidade Vale do Rio Verde - UninCor claudia.hdzfashion@gmail.com

Leiner Marchetti Pereira Universidade Vale do Rio Verde - UninCor leiner.pereira@unincor.edu.br

\section{O IMBRÓGLIO DA INSTITUIÇÃO E DOS EFEITOS DO NOVO REGIME FISCAL DO BRASIL}

\section{RESUMO}

Este artigo irá discorrer sobre um dos temas mais expressivos e polêmicos dos últimos anos, qual seja, o imbróglio da instituição e dos efeitos do Novo Regime Fiscal do Brasil. O assunto aludido, produziu ampla e relevante repercussão nacional, trazendo consigo impetuosos protestos e debates por vasta parte da sociedade civil brasileira, desde o seu método de elaboração, pelo Poder Executivo, e que, até então subsiste, pois, ao final dos trâmites legais, foi incorporado à Constituição Federal, no dia 15 de dezembro de 2016, como Emenda Constitucional $n^{\circ} 95$. Referida Emenda, instituiu um rígido mecanismo de controle de gastos às despesas primárias da União, aquelas utilizadas com a máquina pública e os serviços públicos ofertados à população. Não obstante sua recepção, faz-se crucial compreender o tema, uma vez que, além das inúmeras divergências relativas ao assunto explorado, a norma constitucional em apreço se deu em um estágio de acentuada estagnação financeira e recessão econômica. Assim, buscou-se analisar e assimilar a instituição e os efeitos do Novo Regime Fiscal frente a Constituição Cidadã promulgada na tarde de 05 de outubro de 1988. Destarte, ao final, foi possível ultimar que, a Emenda supracitada, a qual, implementou o Novo Regime Fiscal no Brasil, profana cláusulas pétreas, e a dimensão de seus efeitos opõe-se a direitos fundamentais e princípios soberanos, cânone e sol da Carta Magna.

Palavras-chave: Emenda Constitucional 95/2016. Limitações Despesas Públicas. Direitos Fundamentais. Cláusula Pétrea. Violação.

\section{THE IMBROGLIO OF THE INSTITUTION AND THE EFFECTS OF THE NEW FISCAL REGIME OF BRAZIL}

\begin{abstract}
This article will discuss one of the most expressive and controversial themes of recent years, namely, the imbroglio of the institution and the effects of the New Brazilian Tax Regime. The subject mentioned has produced a wide and relevant national repercussion, bringing with it impetuous protests and debates by a large part of the Brazilian civil society, from its method of elaboration, by the Executive Power, and that until then subsists, therefore, at the end of the legal proceedings, was incorporated into the Federal Constitution, on December 15, 2016, as Constitutional Amendment No. 95. This amendment instituted a rigid mechanism to control expenditures for the Union's primary expenditures, those used with the public machine and the public services offered to population. Notwithstanding its reception, it is crucial to understand the theme, since, in addition to the numerous divergences regarding the subject explored, the constitutional
\end{abstract}


norm in question occurred at a stage of marked financial stagnation and economic recession. Thus, it was sought to analyze and assimilate the institution and effects of the New Tax Regime vis-à-vis the Citizen Constitution promulgated on the afternoon of October 5, 1988. Thus, in the end, it was possible to finalize that, the aforementioned Amendment, which, New Fiscal Regime in Brazil, defers stony clauses, and the dimension of its effects is opposed to fundamental rights and sovereign principles, canon and sun of the Magna Carta..

Keywords: Constitutional Amendment 95/2016. Limitations Public Expenses. Fundamental rights. Petty Clause. Violation.

Recebido em: 05/06/2018 - Aprovado em: 01/10/2018 - Disponibilizado em: 15/12/2018

\section{INTRODUÇÃO}

Considerado como um tema dúbio, o imbróglio do Novo Regime Fiscal, instituído no Brasil, fruto da elaboração do Poder Constituinte Derivado Reformador, não é mais um tema inédito em nosso ordenamento jurídico. Conquanto esteja distante de se chegar a uma percepção uniforme atinente ao assunto em questão, mormente no que se refere aos seus efeitos e constitucionalidade, faz-se crucial explorar essa temática.

Dito regime, suscitou ampla e destacada repercussão nacional, desde o seu método de elaboração, advindo através do Poder Executivo, e que, até então subsiste, pois, inobstante aos incansáveis e impetuosos debates e protestos entre a população, políticos, sindicatos e associações, na tentativa de obstar a instituição do mesmo, ao final dos trâmites legais, este, consolidou-se através da Emenda Constitucional ${ }^{\circ} 95$, a qual foi promulgada e incorporada à Constituição Federal no dia 15 de dezembro de 2016.

De se ressaltar que, a crise econômica que assolou o país, iniciada em gestões precedentes, juntamente com a corrupção generalizada no governo, conduziu a nação a um declínio financeiro consubstanciado por um déficit nas contas públicas, fato este, que levou os governantes do país a cogitar um novo modelo fiscal, tendo como única justificativa, a busca pelo reequilíbrio dos cofres públicos.

Fato é que, mesmo não espelhando a real vontade de grande maioria da população, e, ainda que, tenham sido exibidas inúmeras alternativas a instituição do Novo Regime Fiscal, dado sua complexidade, este, foi aprovado pelo Congresso Nacional, atravessando o rígido sistema imposto para emenda à Constituição.

Logo, por existirem divergências pertinentes ao tema explorado, bem como, por versar sobre um assunto expressivo, eis que, seus efeitos, positivos ou não, atingirão a vida de toda sociedade civil brasileira, o presente artigo tem como objeto precípuo auscultar, assimilar e elucidar, de forma didática, tanto quanto possível, o imbróglio da instituição e dos efeitos do Novo Regime Fiscal frente à Constituição Cidadã de 1988. 


\section{A CONSTITUiÇÃo CIDAdã E O PODER CONSTITUINTE \\ DERIVADO \\ REFORMADOR}

Na tarde do dia 5 de outubro de 1988, o então timoneiro das Diretas Já, o Deputado Federal Ulisses Guimarães, Presidente da Assembleia Nacional Constituinte, declarou promulgada a constituição cidadã, assim chamada por haver ampla participação popular em sua elaboração e especialmente porque se voltou decididamente para a plena realização da cidadania, sendo, neste momento, pronunciada as seguintes palavras históricas: "Declaro promulgado o documento da liberdade, da democracia e da justiça social do Brasil”.

Luís Roberto Barroso (2013, p. 26), assinala que:

A Constituição de 1988 é o símbolo maior de uma história de sucesso: a transição de um Estado autoritário, intolerante e muitas vezes violento, para um Estado democrático de direito.

Pode-se dizer que, a Constituição de 1988 marcou o processo de redemocratização, pois, buscou-se restituir ao povo, direitos que haviam sido retirados durante o regime anterior.

De acordo com Marcelo Alexandrino e Vicente Paulo (2017, p. 31):

Pode-se afirmar que a Constituição de 1988 pretendeu dar ao Brasil a feição de uma socialdemocracia, de criar um verdadeiro Estado Democrático-Social de Direito.
Torna-se cada vez mais distante alcançar o que foi anelado com a promulgação da Carta de 88, pode-se dizer que, a esperança de dias melhores, tão sonhada pelo Constituinte Originário restou-se ludibriada. Garantias constitucionais são desrespeitadas e vilipendiadas. A corrupção ostensiva e generalizada no governo conduziu nosso rico país à bancarrota, resultando numa dívida pública altíssima. Os recursos públicos ficaram escassos para despesas básicas, escassez de investimentos, e toda sorte de problemas típicos de uma administração pública má conduzida e não comprometida com a moralidade.

É possível vislumbrar que, inobstante suas limitações, o Poder Constituinte Derivado Reformador tem adotado uma postura extremamente autoritária e desatinada, emitindo reiteradamente pensamentos, valores e princípios indubitavelmente distintos daqueles que o criou.

Para compreender esse poder de reforma, José Afonso da Silva, apresenta o conceito elaborado pelo Prof. Manoel Gonçalves Ferreira Filho, de que poder constitucional de reforma "é aquele poder, inerente à Constituição rígida que se destina a modificar essa Constituição segundo o que a mesma estabelece [...]". (SILVA, 2017, p. 67). Ou seja, ao efetuar modificações no texto Constitucional, deve-se atentar ao que foi estabelecido inicialmente pelo Constituinte Originário, não podendo haver excesso ou inobservância de normas, regras e princípios preestabelecidos.

Algumas das reformas incorporadas ao texto constitucional, através de emendas, "parecem" extrapolar suas limitações e se tratarem de "meras articulações políticas", comprometendo negativamente o futuro do país. Pode-se citar como exemplo, e passar a explorar 
de forma lacônica, uma das alterações mais expressivas e polêmicas dos últimos anos, inclusive, objeto que resultou na presente pesquisa, qual seja, a Emenda Constitucional $n^{\circ}$ 95/2016.

\section{CONTEXTO HISTÓRICO E JURÍDICO DA EMENDA CONSTITUCIONAL 95/2016}

O procedimento de Emenda à Constituição é rígido e deve transcorrer nos termos do art. 60 da Constituição Federal, posto que, tenciona preservar o que inicialmente foi estabelecido pelo constituinte originário.

No caso concreto, a proposta de emenda à Constituição com o escopo de equilibrar as contas públicas, por meio de um rígido mecanismo de controle de gastos, foi apreciada, discutida e ao final aprovada. Referida Emenda, implementou um Novo Regime Fiscal, nos termos dos arts. 106 a 114 do ADCT, estabelecendo, para cada exercício, limites individualizados para as despesas primárias, aquelas rigorosamente utilizadas com a máquina pública e os serviços públicos ofertados à sociedade em geral, como por exemplo, saúde, educação, previdência, assistência social, e outros. Tal regime vigorará pelos próximos 20 exercícios financeiros, até o ano de 2036.

Conforme dicção do art. 108 do ADCT, somente haverá a possibilidade de alteração dos limites estipulados, a partir do décimo exercício de vigência do Novo Regime Fiscal, podendo ser a alteração proposta uma única vez por mandato presidencial, mediante projeto de lei complementar e por iniciativa do Presidente da República. Pelo art. 109 do ADCT, em caso de descumpri- mento das limitações estabelecidas, impõe-se diversas punições aos órgãos ou poderes atingidos pela mesma, como por exemplo: proibições de contratação de pessoal, reajustes salariais aos quadros funcionais, criação de despesas obrigatórias, realização de concursos públicos, entre outras sanções previstas.

Por um lado, não se pode ignorar o desolado quadro fiscal e econômico que vem aniquilando as contas públicas nos últimos anos.

Enfatiza o escritor José Luis Oreiro (2017, p. 75) que:

A grande recessão iniciada no segundo trimestre de 2014 é a mais profunda e duradoura queda do nível de atividade econômica desde o término da Segunda Guerra Mundial.

Ademais, conforme se expressa Antônio Corrêa de Lacerda:

A retomada do crescimento se apresenta como um dos grandes desafios para a sociedade brasileira após dois anos de profunda crise, em 2015 e 2016. (LACERDA, 2017, p. 37).

Assim, significa dizer que, tal cenário carece de medidas urgentes, coerentes e responsáveis, postura que se espera de um governo. Sucede que, para tal, é primordial crivar um diagnóstico exato, que seja realmente capaz de reequilibrar as finanças públicas do Brasil e não apenas hipóteses.

Mesmo diante da situação fiscal acima explorada, a promulgação da $\mathrm{EC} \mathrm{n}^{\circ}$ 95/2016, foi criticada por grande parte da sociedade civil. 
Pesquisa efetuada pelo instituto Datafolha (2016), demonstrou que a medida não agradou a maioria, uma vez que, para $62 \%$ a EC trará mais prejuízos do que benefícios. Além disso, nos termos da pesquisa, é apontada como inconstitucional.

Todavia, para Matias-Pereira (2017):

O novo regime fiscal se apresenta como uma alternativa adequada para permitir que o Brasil saia da grave crise fiscal. Optou-se por um ajuste mais brando, diluindo esse ajuste ao longo dos próximos 20 anos. A adoção de uma política fiscal mais austera e efetiva, contribui para aumentar a confiança do mercado e dos investidores [...] A instituição do novo regime fiscal, que vai limitar os gastos públicos, se mostrou necessária para impedir que o governo comprometa recursos públicos acima do que o Estado pode dispender.

Detalhe elementar, concernente ao conteúdo abordado, é a posição de Antônio Augusto de Queiroz (2017):

A Emenda à Constituição $\mathrm{n}^{\circ}$ 95/2016, que institui o novo regime fiscal com crescimento real zero da despesa não financeira por 20 anos, determina que o ajuste nas contas públicas seja feito apenas pelo lado da despesa. Eventual aumento de receita não poderá ser gasto com despesa primária ou corrente, devendo ser integralmente destinado à redução do déficit ou à criação de superávit primário. Isto significa que, se o país voltar a crescer, e as receitas de tributos aumentarem, o governo não poderá utilizar esses novos recursos em favor da população, por intermédio da ampliação ou melhoria dos serviços públicos, já que só poderão ser usados para reduzir déficit orçamentário ou para gerar superávit primário, destinados ao pagamento de juros e à amortização da dívida pública.

Assim, restou-se evidente que, a norma constitucional em apreço, acarretou muitas concepções opostas, nas quais se diferem quanto à sua instituição, constitucionalidade e hipotéticos efeitos em virtude do Novo Regime Fiscal.

Há que se considerar que, pelas colocações até aqui abordadas, constata-se que, o Novo Regime Fiscal ocasionou um quadro de vasto temor e hesitações, eis que, dentre outras dimensões, buscou-se diminuir o déficit das contas públicas em detrimento de investimentos que esvaziam os direitos sociais. Neste sentido, já dizia Amartya Sen:

$\mathrm{O}$ que as pessoas conseguem positivamente realizar é influenciado por oportunidades econômicas, liberdades políticas, poderes sociais e por condições habilitadoras como boa saúde, educação básica e incentivo e aperfeiçoamento de iniciativas. (SEN, 2000, p. 19).

Pode-se inferir que, a mitigação dos direitos sociais, expostas pela Emenda, leva a um 
retrocesso dos direitos e garantias fundamentais angariados na Constituição, que por sua natureza programática já são extremamente limitados aos meios e recursos oferecidos pelo Estado.

Neste diapasão, resta inquirir e ultimar, se efetivamente a supradita Emenda Constitucional é uma afronta à Constituição Federal de 1988 e, consequentemente, evidenciar seus efeitos.

\section{DA INCONSTITUCIONALIDADE DO NOVO REGIME FISCAL E SEUS EFEITOS}

Para alicerçar a análise referente à inconstitucionalidade da referida Emenda, utilizarse-á como ponto de partida, a exclamação feita por Ulysses Guimarães quando da promulgação da Carta Magna:

\begin{abstract}
A Constituição certamente não é perfeita. Ela própria o confessa, ao admitir a reforma. Quanto a ela, discordar, sim. Divergir, sim. Descumprir, jamais. Afrontá-la, nunca. Traidor da Constituição é traidor da Pátria. (GUIMARÃES, 1988).
\end{abstract}

Cabe esclarecer que, o procedimento de Emenda à Constituição encontra-se consubstanciado na conformidade com o disposto no art. 60 da $\mathrm{CR} / 88$, sob pena de incorrer-se em insanável vício.

Por sua vez, na clara lição de Paulo Bonavides (2017, p. 213):

Toda Constituição pode ser emendada, salvo a matéria constante de exclusão em virtude dos limites expressos e tácitos postos à ação inovadora do constituinte de segundo grau, aquele dotado apenas de competência constituinte constituída ou derivada, isto é, que procede de vontade absoluta e soberana do constituinte originário. Os limites expressos cuja transgressão ocasiona a inconstitucionalidade da iniciativa de emenda, fazendo com que a proposta não seja sequer objeto de deliberação, são aqueles contidos no $\S$ $4^{\circ}$ do art. 60 da Constituição. [...] Mas o poder de emenda não se acha tolhido apenas por esses limites que acabamos de enunciar. Há outros não menos importantes e de igual eficácia que decorrem da natureza das instituições e são invioláveis; feri-los importaria suprimir a razão de ser da ordem constitucional e quebrantar o espírito da nossa forma de Estado de Direito abraçado à ideologia das liberdades democráticas.

Insta ressaltar que, o simples desígnio de subverter os valores vitais compreendidos no cerne das cláusulas pétreas, previstas no $\S 4^{\circ}$ do art. 60 da Carta da República, já caracteriza afronta ao texto constitucional, basta que a exegese do teor da Emenda, demonstre a pretensão de alterar, mesmo que indiretamente, a estrutura constitucional organizada.

Nesta ótica, cumpre indicar os apontamentos as inconstitucionalidades da Emenda em comento. Sobre o assunto, acentuou 
Ronaldo Jorge Araújo Vieira Júnior no Boletim

Legislativo do Núcleo de Estudos e Pesquisas do

Senado Federal $\mathrm{n}^{\mathrm{o}}$ 53, quanto à inconstitucionalidade da $\operatorname{PEC~} \mathrm{n}^{\circ} 55$, embrião da Emenda Constitucional 95/2016:

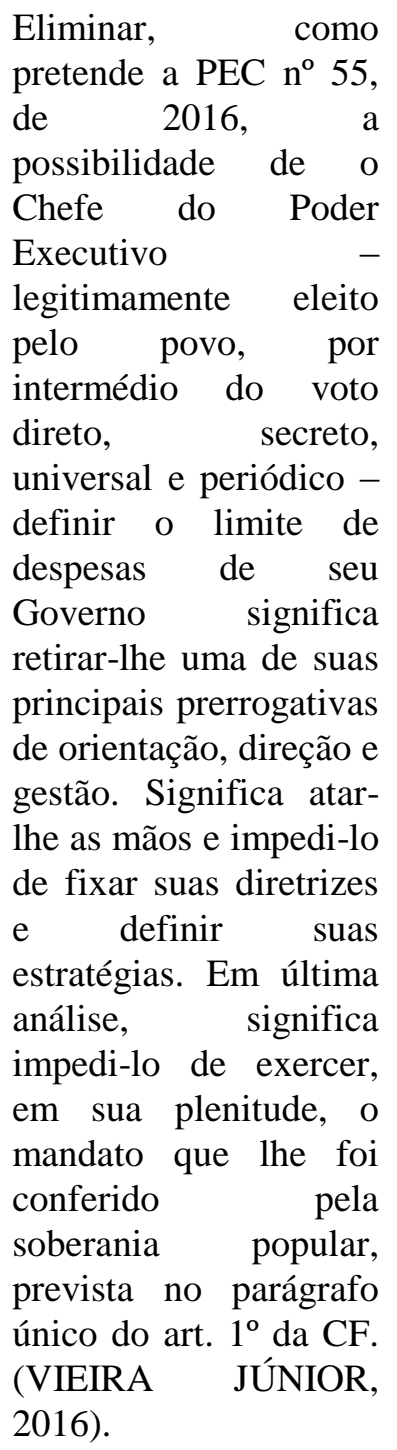

Por outro lado, quanto à afronta a separação dos Poderes, dispôs a Secretaria de Relações Institucionais da Procuradoria-Geral da República em Nota Técnica que:

[...] a autonomia administrativa e financeira assegurada ao Poder Judiciário e a autonomia funcional e administrativa assegurada ao

Ministério Público e às

Defensorias Públicas

são elementos

indispensáveis para que essas instituições exerçam suas funções constitucionais com independência, sempre voltadas para a proteção dos direitos fundamentais [...] Com efeito, a proposta em tela, que pretende impor limitação orçamentária venenaria e que toma por parâmetro exercício financeiro (2016) marcado por um agressivo corte orçamentário [...] conforme amplamente divulgado na mídia, implica,

inexoravelmente, no enfraquecimento das instituições do Estado. [...] Com efeito, a partir do momento em que se propõe uma limitação de gastos públicos conforme apresentado pela PEC 241, por vinte anos, percebe-se, claramente, que a proposta de emenda tende a afrontar a independência e autonomia dos Poderes Legislativo e Judiciário e a autonomia das instituições do Sistema de Justiça (Funções Essenciais à Justiça, em especial o Ministério Público e as Defensorias Públicas), razão pela qual, respeitosamente, a Proposta de Emenda à Constituição (PEC) 241, de 2016 é inconstitucional.

(PGR/SRI $\mathrm{N}^{\mathrm{o}}$ 82, 2016). 
Como se vê, ao impor limitações aos órgãos supramencionados, foi violada a separação e a independência dos poderes, ficando mais uma vez demonstrada patente inconstitucionalidade da norma.

Não obstante as violações normativas já exteriorizadas, cumpre razoar ainda, sobre a mais esdrúxula de todas elas, ou seja, a ofensa aos direitos e garantias individuais. Assim, faz-se oportuno avultar a indagação denotada por Marcelo Alexandrino e Vicente Paulo (2017, p. 595):

[...] faz-se mister
responder a indagação
seguinte: Estariam
protegidos sobre o
pálio da cláusula pétrea
exclusivamente os
direitos e garantias
arrolados no art. $5^{\circ}$ da
Constituição Federal?
O Supremo Tribunal
Federal decidiu que
não, entendendo que a
garantia insculpida no
art. $60, \S 4^{\circ}$, IV, da CF
alcança um conjunto
mais amplo de direitos
e garantias
constitucionais de
caráter individual
dispersos no texto da
Carta Magna.

Pela sapiência dos constitucionalistas, os direitos e garantias individuas pautados como cláusulas pétreas não se exaurem no repertório do art. $5^{\circ}$ da $\mathrm{CR} / 88$. Incluem-se, os princípios constitucionais e os direitos sociais previstos no art. $6^{\circ}$, destacando-se entre eles, saúde e educação, tratando-se, portanto, de cláusulas pétreas. Note-se que, no contexto do Novo Regime Fiscal os direitos e garantias individuais, foram vilipendiados, fato incongruente e inconstitucional.

De forma breve e em linhas gerais, sem adentrar as minúcias relativas ao tema, o texto insculpido na EC 95/2016, ao engessar os gastos primários da União por um período de 20 anos, e mais, estipulando como parâmetro o ano de 2016, o qual foi extremamente instável e precário, resulta, ainda, na afronta aos princípios basilares da República Federativa, primordialmente, os princípios da vedação ao retrocesso social e da dignidade da pessoa humana, fato este que, frustra completamente o implemento dos objetivos fundamentais da Constituição da República, pactuados no artigo $3^{\circ}$ da Carta Magna.

Dentro dessa mesma ótica, fato demasiadamente pertinente, é que, a eficácia jurídica da Emenda Constitucional no 95/2016 encontra-se demasiadamente ameaçada. Segundo notícias do STF (2017), já existem 06 (seis) Ações Diretas de Inconstitucionalidade propostas no Supremo Tribunal Federal questionando o texto da supradita emenda, isso, com o escopo de obter a declaração de sua inconstitucionalidade, melhor especificando, são elas: ADI's 5715 e 5734, ajuizadas respectivamente pelo Partido dos Trabalhadores e pela Confederação Nacional dos Trabalhadores em Educação, ADI 5633, proposta pela Associação dos Magistrados Brasileiros, Associação Nacional dos Magistrados da Justiça do Trabalho e pela Associação dos Juízes Federais do Brasil, ADI 5643, ajuizada pela Federação Nacional dos Servidores e Empregados Públicos Estaduais e do Distrito Federal, ADI 5658, apresentada pelo Partido 
Democrático Trabalhista e a ADI 5680, de autoria do Partido Socialismo e Solidariedade.

\section{CONSIDERAÇÕES FINAIS}

Os esplêndidos objetivos, fundamentos e direitos, fixados pelo Constituinte Originário no contexto da Constituição Cidadã de 1988, lamentavelmente, não foram, sequer, objeto de elucubração por parte do Poder Constituinte Derivado Reformador, quando da promulgação da Emenda Constitucional $n^{\circ}$ 95/2016, a qual, implementou o Novo Regime Fiscal no Brasil.

Convencionar um engessamento no orçamento público e aplicação de seus recursos, restringindo as despesas primárias da União, por um ínterim de vinte longos anos, é medida paradoxal. O Novo Regime Fiscal, dissipa a democracia e o pacto social de 1988, reduzindo formidavelmente o papel do Estado, o que, não condiz com sua finalidade precípua, qual seja, a busca pelo bem comum, carecendo este, atender à razão natural da vida em sociedade e propiciar a realização das expectativas do homem em busca de seguimentos efetivos que propiciem as necessidades ínfimas de todo e qualquer cidadão, garantindo e proporcionando a dignidade da pessoa humana, rudimento da Carta Magna.

Os efeitos do Novo Regime Fiscal são perversos e abomináveis, pois, levou-se sobre os ombros do trabalhador brasileiro o ônus dos erros de governos corruptos e levianos na administração de seus recursos, fazendo do corpo social, precipuamente das parcelas mais desfavorecidas, as únicas degustadoras do "remédio amargo" estritamente vital, que foi obrigatoriamente introduzido nas veias da população brasileira, o que, suscitará efeitos colaterais deletérios e repugnantes, expandindo os níveis de desigualdade em uma nação excessivamente desigual, fomentando um sistema feudal onde os trabalhadores sustentam seus senhores do sistema financeiro.

É patente que, quando da elaboração do Novo Regime Fiscal, foi priorizado o sistema tributário e financeiro, deixando em segundo plano os princípios e direitos fundamentais contidos no texto constitucional, sobretudo os direitos sociais, os quais perderam de vez sua guarida estatal, é inverossímil, mas, a partir deste momento, o Estado deixa de ser garantidor e provedor do bem-estar social, passando a ser provedor de política fiscal em detrimento da social, o que não é uma medida congruente.

Neste prisma, não se nega a imprescindibilidade da instituição de um Regime Fiscal que dê sustentação ao país e, consequentemente, alavanque a economia, é sabido e ressabido que uma política fiscal é alicerce e parâmetro de sucesso de uma nação, haja vista que, traz confiança e investimentos ao país, elevando-o a um círculo virtuoso, viabilizando, através desta, o cumprimento das finalidades precípuas do Estado, ocorre que, para tanto, isso deve suceder de forma precisa, e não conforme propenso no texto da Emenda Constitucional $n^{\circ}$ 95/2016, já que, é imperioso alicerçar-se na Constituição Federal e ter um equilíbrio entre ambos os setores e não o martírio de um em detrimento do outro.

\section{REFERÊNCIAS}

ALSTON, P. Carta Capital. PEC 55 é "erro histórico" que provocará "retrocesso social", diz ONU. São Paulo, 09/12/2016. Disponível em: $<$ https://www.cartacapital.com.br/politica/pec-55-e- 
erro-historico-que-provocara-retrocesso-social-dizonu>. Acesso em: 22 de maio de 2018.

\section{BARROSO, L. R. O Novo Direito Constitucional} Brasileiro: Contribuições Para a Construção Teórica e Prática da Jurisdição Constitucional no Brasil. Belo Horizonte: Fórum, 2013.

BONAVIDES, P. Curso de Direito Constitucional. 32 ed. São Paulo: Malheiros, 2017.

BRASIL. Constituição (1988). Constituição da República Federativa do Brasil. Brasília, DF. Senado Federal: Centro Gráfico, 1988.

BRASIL. Emenda Constitucional no 95, de 15 de dezembro de 2016. Brasília: Presidência da República do Brasil, 2016. Disponível em:

<http://www.planalto.gov.br/ccivil_03/constituicao/em endas/emc/emc95.htm>. Acesso em: 15 de março de 2018.

BRASIL. Supremo Tribunal Federal. Novas ações questionam emenda constitucional que limita gastos públicos. Notícias STF, Brasília, 11/07/2017. Disponível em:

<http://www.stf.jus.br/portal/cms/verNoticiaDetalhe.a sp? idConteudo $=349227 \&$ caixaBusca $=N>$. Acesso em: 20 de maio de 2018.

DATAFOLHA. Maioria é contra aprovação da PEC 55. Instituto de Pesquisa Datafolha, São Paulo, 13/12/2016. Disponível em:

<http://datafolha.folha.uol.com.br/opiniaopublica/201 6/12/1840963-maioria-e-contra-aprovacao-da-pec55.shtml>. Acesso em: 11 de março de 2018.

EBC AGÊNCIA BRASIL. Emenda do Teto dos Gastos Públicos é promulgada e entra em vigor. Brasília, 15/12/2016. Disponível em:

<http://agenciabrasil.ebc.com.br/geral/noticia/2016-

12/emenda-do-teto-dos-gastos-publicos-e-

promulgada>. Acesso em: 15 de março de 2018.

FERrEIRA FILHO, M. G. Curso de Direito Constitucional. 26 ${ }^{\mathrm{a}}$ Ed. São Paulo: Saraiva, 1999.

GUIMARÃES, U. Agência Senado. Em discurso histórico, Ulysses Guimarães comemora a promulgação da Carta de 1988. 29/09/2008. Disponível em: <http://www12.senado.leg.br/noticias/materias/2008/0 9/29/em-discurso-historico-ulysses-guimaraescomemora-a-promulgacao-da-carta-de-1988>. Acesso em: 15 de março de 2018.

IFCH. Unicamp aprova moção contra PEC 55. 2016. Instituto de Filosofia e Ciências Humanas da Unicamp. Campinas-SP. 02/12/2016. Disponível em: $<$ https://www.fe.unicamp.br/institucional/noticias/unic amp-aprova-mocao-contra-pec-55>. Acesso em: $20 \mathrm{de}$ março de 2018.
LACERDA, A. C. Estudos Avançados. São Paulo: Universidade de São Paulo-USP. 1987. Vol.31. No 89. Jan/Abr. 2017. ISSN 0103-4014.

\section{MATIAS-PEREIRA, J. Crise Econômica-Política-} Ética no Brasil: Uma Avaliação das Motivações, Equívocos e Efeitos nas Finanças Públicas. Revista Observatorio de la Economía Latinoamericana, Brasil, 03/2017. Disponível em: <

http://www.eumed.net/cursecon/ecolat/br/17/crise.htm 1>. Acesso em: 12 de março de 2018.

OREIRO, J. L. Estudos Avançados. São Paulo: Universidade de São Paulo-USP. 1987. Vol.31. № 89. Jan/Abr. 2017. ISSN 0103-4014.

PAUlO, V.; ALEXANDRINO, M. Direito Constitucional Descomplicado. $16^{\mathrm{a}} \mathrm{Ed}$. Rio de Janeiro: Forense; São Paulo: Método, 2017.

PGR. PROCURADORIA GERAL DA REPÚBLICA. Nota Técnica PGR/SRI No 82/2016. Ementa: Proposta de Emenda à Constituição (PEC) 241, de 2016, que altera o Ato das Disposições Constitucionais Transitórias (ADCT) para instituir o "Novo Regime Fiscal". Brasília, DF. 2016.

QUEIROZ, A. A. O teto de gastos, os serviços e os servidores públicos. Congresso em Foco, BrasíliaDF, 26/07/2017. Disponível em: <

http://m.congressoemfoco.uol.com.br/opiniao/colunist as/o-teto-de-gastos-os-servicos-e-os-servidorespublicos/>. Acesso em: 18 de abril de 2018.

SEN, A. K. Desenvolvimento como liberdade. Tradução Laura Teixeira Motta. São Paulo: Companhia das Letras, 2000.

SILVA, J. A. da. Curso de Direito Constitucional Positivo. 40ª Ed. São Paulo: Malheiros, 2017.

VIEIRA JÚNIOR, R. J. A. As Inconstitucionalidades do "Novo Regime Fiscal" Instituído pela PEC no 55, de 2016 (PEC n 241, de 2016, na Câmara dos Deputados). Brasília: Núcleo de Estudos e Pesquisas da Consultoria Legislativa/CONLEG/Senado, novembro/2016 (Boletim Legislativo $\mathbf{n}^{\mathbf{0}}$ 53, de 2016). Disponível em: www.senado.leg.br/estudos. Acesso em: 03 de maio de 2018.

\section{Cláudia Pereira da Silva}

Discente do Curso de Direito da Universidade Vale do Rio Verde - UninCor.

\section{Leiner Marchetti Pereira}

Mestre em Direito. Coordenador do Curso de Direito da Universidade Vale do Rio Verde - UninCor. 